\title{
Editorial
}

\section{Extreme Precipitation and Floods: Monitoring, Modelling, and Forecasting}

\author{
Zheng Duan, ${ }^{1}$ Hongkai Gao, ${ }^{2,3}$ and Mouleong $\operatorname{Tan}^{4}$ \\ ${ }^{1}$ Chair of Hydrology and River Basin Management, Technical University of Munich, Arcisstrasse 21, 80333 Munich, Germany \\ ${ }^{2}$ Guangdong Engineering Technology Research Center of Water Security Regulation and Control for Southern China, Sun Yat-sen \\ University, Guangzhou 510275, China \\ ${ }^{3}$ Julie Ann Wrigley Global Institute of Sustainability, Arizona State University, Tempe, AZ 85287, USA \\ ${ }^{4}$ Geography Section, School of Humanities, Universiti Sains Malaysia, 11800 Penang, Malaysia
}

Correspondence should be addressed to Zheng Duan; duanzheng2008@gmail.com

Received 27 July 2017; Accepted 30 July 2017; Published 30 August 2017

Copyright (C) 2017 Zheng Duan et al. This is an open access article distributed under the Creative Commons Attribution License, which permits unrestricted use, distribution, and reproduction in any medium, provided the original work is properly cited.

Flooding is one of the leading natural hazards [1]. Floods often cause enormous casualties and substantial property damage on a global scale every year. Extreme precipitation along with increasing urbanization is the main culprit of most floods. Under climate change, increases in extreme precipitation are projected for the United States and other countries. Understanding the mechanisms of extreme precipitation and its hydrometeorological connection with flooding, especially under the circumstances of global climate change, is essential for flood prevention and mitigation. Extreme precipitation and flood monitoring are traditionally obtained from in situ observations. However, remote sensing provides us with various hydrological and meteorological retrievals at a range of temporal and spatial resolutions. Remotely sensed data alone and their integration with modelling techniques are expected to enhance flood monitoring and modelling capability to aid in decision-making. There is an urgent need for improved monitoring, modelling, and forecasting techniques in extreme precipitation to develop more effective flood protection measures and management.

The aim of this special issue is to present and discuss the current scientific and technological developments on extreme precipitation estimation, flood monitoring, and flood modelling, with the end goal of improving flood prevention and mitigation. This special issue is intended to cover a wide range of relevant topics, such as in situ measurement and remote sensing of extreme precipitation, rainfall-runoff modelling, statistical and hydrological analysis of extreme precipitation and flood, flood forecasting and warning, and impact assessment of climate change and land use/cover change on flood. This special issue attracted a total number of 26 submissions and finally 5 papers were accepted. A brief overview of these five papers is summarized as follows.

(i) A range of gridded precipitation products at different spatial and temporal resolutions over the global or quasi-global scale have been developed over recent decades [2]. The advantages (e.g., the free availability and better ability in monitoring spatial and temporal variability of precipitation) attract applications of gridded precipitation in hydrology and climate studies. However, the accuracy of a certain gridded precipitation product could vary from region to region $[3,4]$. Therefore, it is essential to evaluate the performance of gridded precipitation products in specific regions in order to achieve a global view of their accuracy and to identify directions for further improvements. S. Jiang et al. in "Evaluating the TRMM Multisatellite Precipitation Analysis for Extreme Precipitation and Streamflow in Ganjiang River Basin, China" evaluated two gridded precipitation products in estimation of extreme precipitation and further in the simulation of extreme streamflow when the VIC (Variable Infiltration Capacity) hydrological 
model is forced using these two precipitation products in Ganjiang River Basin, China. The two products are TRMM Multisatellite Precipitation Analysis (TMPA) products, that is, 3B42RTV7 and 3B42V7. TRMM refers to the Tropical Rainfall Measuring Mission. They found that both gridded precipitation products captured the pattern of observed extreme precipitation but overestimated the extreme precipitation for the $95 \%$ threshold. The simulated extreme streamflows from the VIC model when using both products as inputs were found to agree well with the observations. The 3B43V7 had relatively better performance than the 3B42RTV7 in all evaluated aspects.

(ii) Extreme precipitation monitoring plays an important role in flood forecasting, warning, and mitigation. The accuracy of precipitation monitoring is the key to estimating the volume of flooding and the spatial and temporal distribution of inundated area. Weather radar presents a powerful technology to derive the amount of precipitation from radar echo data. However, the complex temporal-spatial variation of raindrop size distribution affects the accuracy of precipitation forecast. Y. Xue et al. in "Regional Attenuation Correction of Weather Radar Using a Distributed Microwave-Links Network" proposed a region attenuation correction algorithm to correct the weather radar echo data. They found that, with the aid of regional attenuation correction method, the accuracy of the corrected radar reflectivity factor was improved by $26 \%$ and the rainfall intensity distribution was improved by $52 \%$. This technical improvement provides a wide range of applications for precipitation monitoring and flood forecasting, warning, and mitigation.

(iii) Heavy rainfall potentially leading to flash flooding is often associated with elevated thunderstorms; an understanding of the physical processes for the development of heavy rainfall producing elevated thunderstorms will be beneficial to improving the prediction of heavy rainfall [5]. L. P. McCoy et al. in "Composites of Heavy Rain Producing Elevated Thunderstorms in the Central United States" performed composite analysis of elevated thunderstorms events producing heavy rainfall (>50 $\mathrm{mm}$ within a 24 -hour period) in Central United States. They presented additional sounding analysis and analysis of variability within the composite mean fields via a measure of interquartile range. These additional analyses can allow for discriminating elevated thunderstorm events that produce heavy rainfall from those sharing many similar atmospheric fields but producing significantly less rainfall. Their results supported existing findings and improved the understanding of the typical synoptic and mesoscale environment favorable for the development of heavy rainfall producing elevated thunderstorms.

(iv) A Regional Frequency Analysis (RFA) of extreme precipitation is vital for providing insights into flood mitigation strategies. S. A. Khan et al. in "Regional Frequency Analysis of Extremes Precipitation Using L-Moments and Partial L-Moments" compared the RFA method based on L-moment and Partial Lmoment (PL-moment) in analyzing extreme precipitation of Northern areas and Khyber Pakhtunkhwa, Pakistan, for a period from 1999 to 2012. The Land PL-moments are derived for generalized extreme value $(\mathrm{GEV})$, generalized logistic (GLO), generalized normal (GNO), and generalized Pareto (GPA) distributions. A Monte Carlo simulation is then used to evaluate the sampling properties of L- and LPmoments. The GEV, GPA, and GNO distributions are similar at the lower tail but different at the upper tail due to a variation between the regional quantiles. The GPA and GNO distributions are suitable for the Lmoment and PL-moment, respectively. In general, the performance of PL-moment is better than L-moment in estimating large return period events in Pakistan.

(v) Physically based hydrodynamic model provides a scientific tool to support decision-making on urban storm water resources management, drainage system designing, sponge city construction, and urban flooding risk control and mitigation. Although river and coastal flooding modelling are relatively well developed, urban flooding modelling is still comparatively underexplored. This is particularly true for the $2 \mathrm{D}$ hydrodynamic modelling. Y. Fan et al. in "A Coupled 1D-2D Hydrodynamic Model for Urban Flood Inundation" coupled a $1 \mathrm{D}$ model with a $2 \mathrm{D}$ model attempting to tackle this issue. Technically, the finite difference method was used to discretize and simplify the Saint-Venant equations into a 1D model. And then an implicit dual time-stepping method (DTS) was applied for 2D inundation simulation to improve computational efficiency. A widely used model (Storm Water Management Model, SWMM) was set as a benchmark to validate the proposed model. Satisfactory results were obtained to reproduce several urban flooding events for both discharge and water depth.

We hope that this special issue would shed light on recent development in topics regarding the monitoring, modelling, and forecasting of extreme precipitation and floods. This special issue calls for more attention to relevant topics to achieve continuous improvements in flood prevention and mitigation.

\section{Acknowledgments}

We would like to thank all the authors for their contributions to this special issue. Thanks also are due to all reviewers for their time and efforts in reviewing the submitted manuscripts, particularly for the constructive comments to improve the quality of the accepted papers.

Zheng Duan

Hongkai Gao

Mouleong Tan 


\section{References}

[1] H. Gao, H. Cai, and Z. Duan, "Understanding the impacts of catchment characteristics on the shape of the storage capacity curve and its influence on flood flows," Hydrology Research, vol. 48, no. 4, 2017.

[2] F. J. Tapiador, F. J. Turk, W. Petersen et al. et al., "Global precipitation measurement: methods, datasets and applications," Atmospheric Research, vol. 104, pp. 70-97, 2012.

[3] Z. Duan, J. Liu, Y. Tuo, G. Chiogna, and M. Disse, "Evaluation of eight high spatial resolution gridded precipitation products in Adige Basin (Italy) at multiple temporal and spatial scales," Science of the Total Environment, vol. 573, pp. 1536-1553, 2016.

[4] M. L. Tan and Z. Duan, "Assessment of GPM and TRMM precipitation products over singapore," Remote Sensing, vol. 9, no. 7, p. 720, 2017.

[5] J. T. Moore, F. H. Glass, C. E. Graves, S. M. Rochette, and M. J. Singer, "The environment of warm-season elevated thunderstorms associated with heavy rainfall over the central United States," Weather and Forecasting, vol. 18, no. 5, pp. 861-878, 2003. 

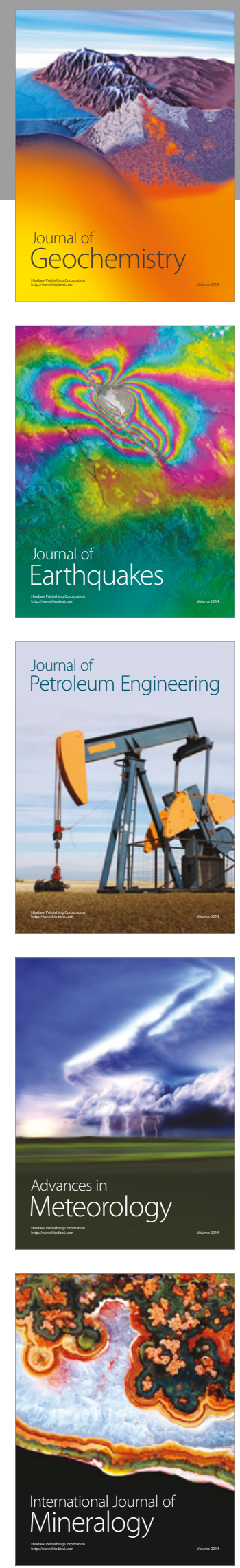
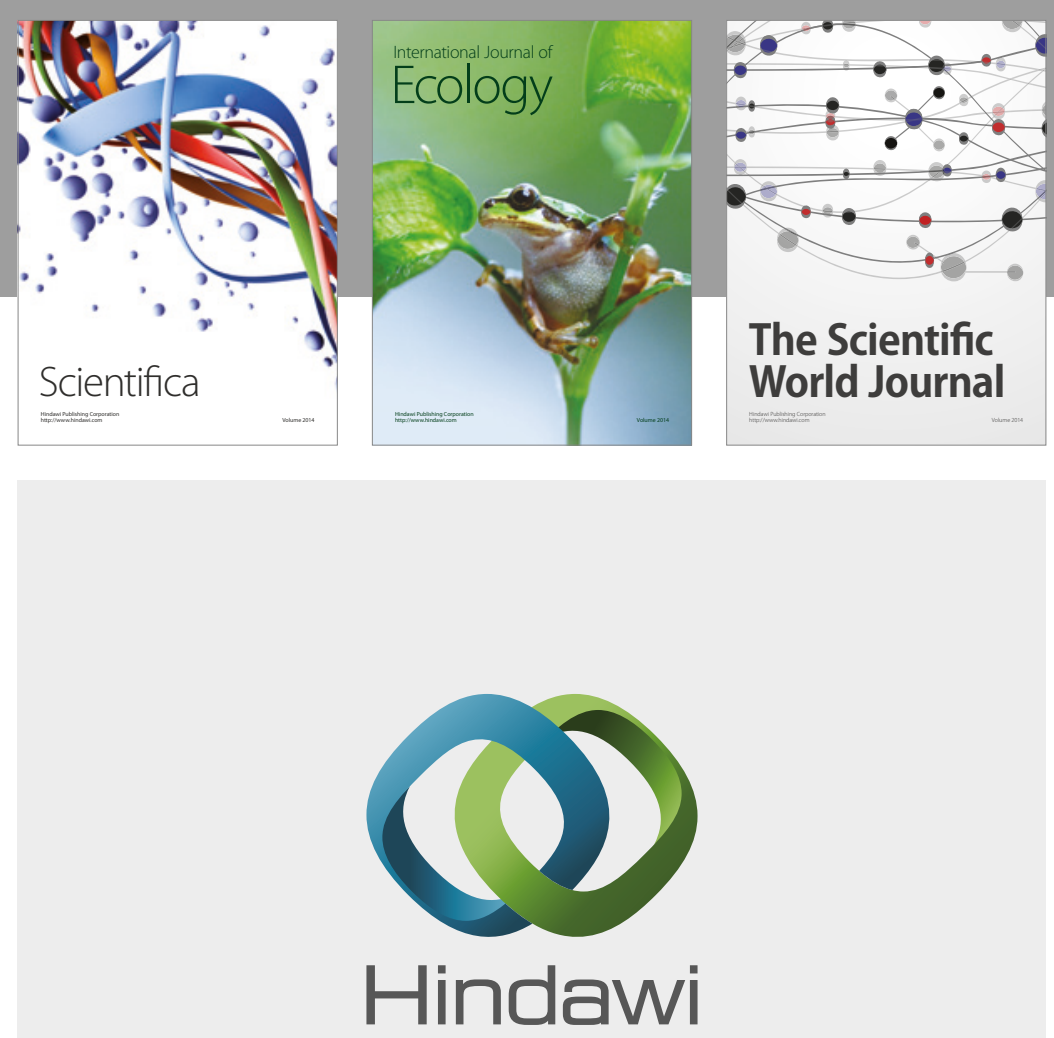

Submit your manuscripts at

https://www.hindawi.com
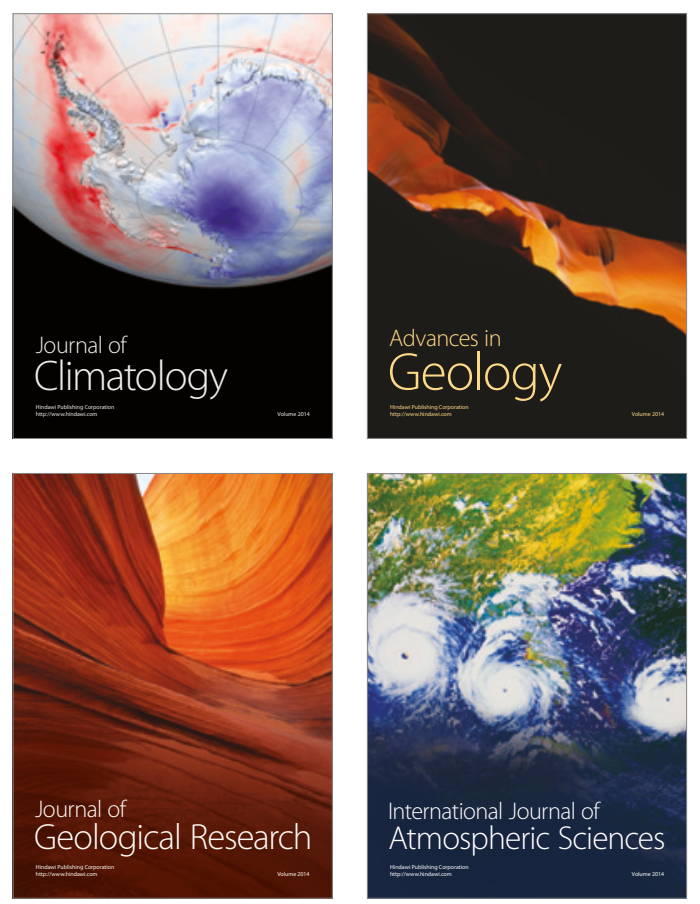

The Scientific

World Journal
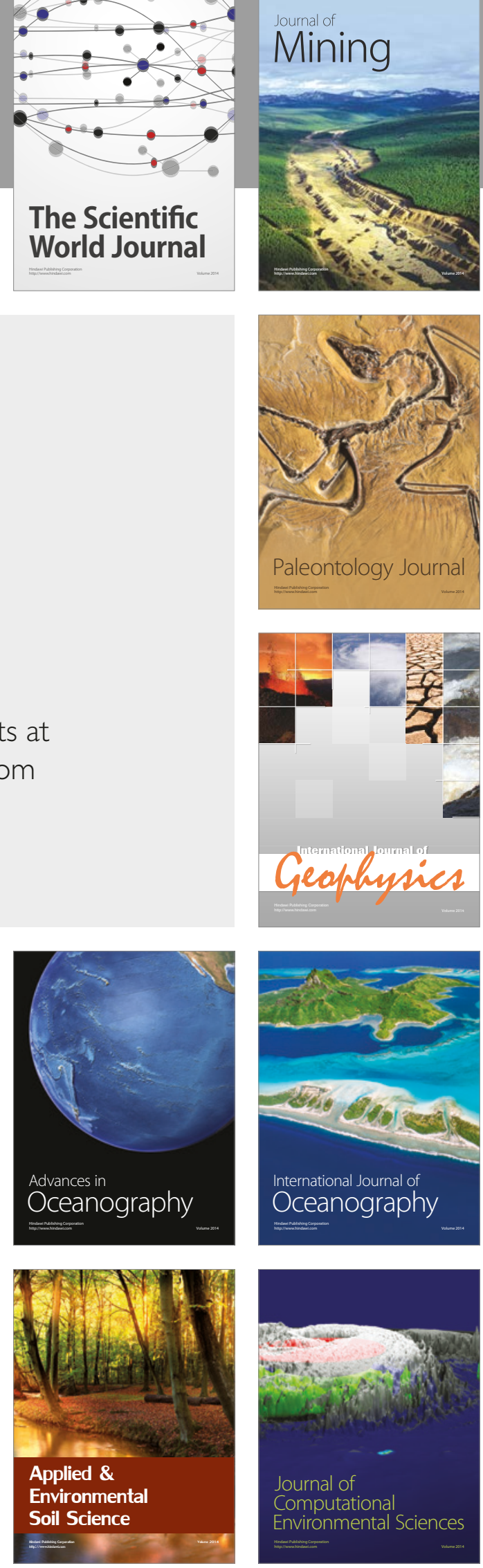